\title{
Lisansüstü Öğrenim Gören Yabancı Öğrencilerin Akademik Türkçe Özyeterliklerine İlişkin Görüşleri ${ }^{1}$
}

DOI: $10.26466 /$ opus.771216

$*$

\author{
Sevil Hasırcı Aksoy * \\ * Dr.Öğr.Üyesi, Gaziantep Üniversitesi \\ E-Posta: sevilhasirci@gmail.com \\ ORCID: $\underline{0000-0003-1041-7558}$
}

\section{Öz}

Yabancı dil olarak Türkçe öğrenen öğrencilerin birçok amacı bulunmaktadır: dilsel becerileri geliştirmek, sosyal-kültürel gereksinimleri karşılamak, akademik ortama uyum sağlamak, Türk dünyasını yakından tanımak,... Bu amaçlardan biri olan akademik ortama uyum sağlamak için akademik dil yetisi ve özyeterliği gerekmektedir. Bu araştırmada lisansüstü öğrenim gören yabancı uyruklu öğrencilerin akademik dil özyeterliklerine ilişkin görüşlerini belirlemek amaçlanmıştır. Bu amaç doğrultusunda Türkçeyi yabancı dil olarak öğrenen bireylerin lisansüstü dersleri anlamakta zorluk yaşayıp yaşamadıkları, Türkçe bilimsel metin okuma sıklıkları ve bilimsel metin okumada zorluk yaşayıp yaşamadıkları, Türkiye'de yapılan kurultay, sempozyum ve çalıştay gibi bilimsel etkinliklere katılma durumları, Türkçe bilimsel metin yazımında zorluk yaşayıp yaşamadıkları ve yaşadıkları zorlukların üstesinden gelmek için neler yaptıklarına ilişkin görüşleri sorgulanmıştır. Bu bağlamda odak grup görüşmesinden yararlanılmıştır. Betimsel analiz ile elde edilen veriler doğrultusunda lisansüstü öğrencilerin akademik Türkçe okuma ve dinlemede güçlük yaşadıkları ve ders içeriği, metnin yapısı, öğretim üyesinin konuşma tarzı gibi değişkenlerin etkili olduğu ve akademik konuşma ile yazmada ise özellikle paragraflar arası bireşim yapma, yeterli bilginin olmaması ve kendini hazır hissetmeme gibi değişkenlerin güçlük yarattı̆̆ı sonucuna ulaşılmışıtır.

Anahtar Kelimeler: Türkçenin yabancı dil olarak öğretimi, akademik Türkçe, lisansüstü öğrenciler.

\footnotetext{
${ }^{1}$ Bu çalışma, 28-29 Kasım 2019 tarihinde Gazi Üniversitesi tarafından düzenlenen "Kuruluşunun 30. Yılında Türkçe Eğitimi Ana Bilim Dallarının Dünü, Bugünü, Yarını" çalıştayında sunulan bildirinin genişletişmiş halidir.
} 
ISSN: 2528-9527

E-ISSN : 2528-9535

Yıl Year: 11

Cilt Volume: 17

Sayı Issue: 35

Mart March 2021

Makalenin Geliş Tarihi Received Date. 20/07/2020

Makalenin Kabul Tarihi Accepted Date. 30/03/2021

\title{
The Opinions of Foreign Students Studying for Graduate Studies Related to Their Academic Turkish Language Self-Efficacy
}

\begin{abstract}
Students who learn Turkish as a foreign language have many goals: developing linguistic skills, meeting social-cultural needs, adapting to the academic environment, getting to know the Turkish world closely. In order to adapt academic environment, students need for academic success and competence. In this study, it was aimed to determine the opinions of foreign graduate students related to their academic Turkish language self-efficacy. For this purpose, students studying for graduate studies and learning Turkish as a foreign language were questioned whether they experienced difficulty in understanding postgraduate courses, in reading and writing Turkish scientific text. And also their opinions were got whether they had participated in the scientific activities in Turkey, and their opinions on overcoming the difficulties. In this context, the focus group interview were utilized. In line with the data obtained through descriptive analysis, graduate students had difficulty in academic reading and listening, and at these difficulties such as course content, text structure, and the speaking style of the instructor were effective. And in academic speaking and writing, it was concluded that variables such as not feeling ready himself, the lack of knowledge and to be unable to synthesize paragraphs created difficulty.
\end{abstract}

Keywords: Turkish teaching as a foreign language, academic Turkish, graduate students. 


\section{Giriş}

Yabancı dil olarak Türkçe öğrenen öğrencilerin dil öğrenme sürecine ilişkin birçok amacı bulunmaktadır: dilsel becerileri geliştirmek, sosyal-kültürel gereksinimleri karşılamak, akademik ortama uyum sağlamak, Türk dünyasını yakından tanımak,... Bu tür gereksinimlerini karşılamak amacıyla Türkiye'de farklı üniversitelerin ya da kurumların bünyesinde yer alan birimlerde hazırlık okuyan öğrenciler, ertesi yıl bölümlerinde akademik bir sürece katılmaktadır. Bu süreçte öğrenciler, yükseköğrenimlerinde dilsel becerilerini işe koşarak akademik başarıya ulaşmayı amaçlamaktadır. Akademik başarı için ise akademik dil yetisi gerekmektedir.

Dil, öğrencilerin etkileşimli katılımlarına olanak tanıyan etkinlikliklerle örülmüş dil kaynakları ile öğrenilir. (Schleppegrell, 2013, s.154). Bu kaynakları etkin bir biçimde kullanmalarında ise öğrencilerin amaçları önemli bir rol oynamaktadır. Barın (2010), bir yabancının Türkiye'de lisans ya da lisansüstü öğrenim görebilmesini sağlayabilmek amacıyla dil öğretimi planlanacaksa öğrenci gereksinimlerine dönük belirlemelerin farklı olabileceğini, bu yönde bir yöntem belirlemek gerektiğini belirtmektedir. Bu yöntem/yöntemler doğrultusunda öğrencilerin okul yıllarındaki her alana dönük istemlerini karşılamalarını sağlayan, anlamlı akademik etkinlikler bağlamında etkileşime katılma olanaklarının yaratılması gerekir (Schleppegrell, 2013, s.154). Akademik dile dönük etkinlikler planlanırken akademik dilin bileşenlerinin neler olduğunun üzerinde durulması, bu etkinliklerin işlevsel hale gelmesini sağlamaktadır.

Akademik dil; dilsel, bilişsel ve sosyokültürel olmak üzere üç yönüyle öne çıkmaktadır (Scarcella, 2003). Bu üç yönüyle akademik dil; içerik alan bilgisi ve sözvarlığı, dilsel yapılar ve işlevleri, içeriğin öne çıktı̆̆ bağlam, eleştirel düşünme becerisi, metin ve sözel/işitsel temelli etkinlikler yoluyla dili yeniden yapılandırmadan oluşmaktadır (Cook Hirai, Borrego, Garza ve Kloock, 2010, s.4). Akademik dili öğretmedeki temel amaç ise öğrencilerin derinlemesine okuma taleplerini karşılamak, çeşitli akademik türlerde yazma becerilerini geliştirmek, dersleri anlamaları ya da derslerde grup tartışmalarına katılmak için akademik çalışmalarında dili etkili bir şekilde kullanmaya hazırlamaktır (Newton, vd., 2018, s.1). Bu hazırlama sürecinde anlama ve anlatma becerilerini işe koşmak başat amaçtır. 


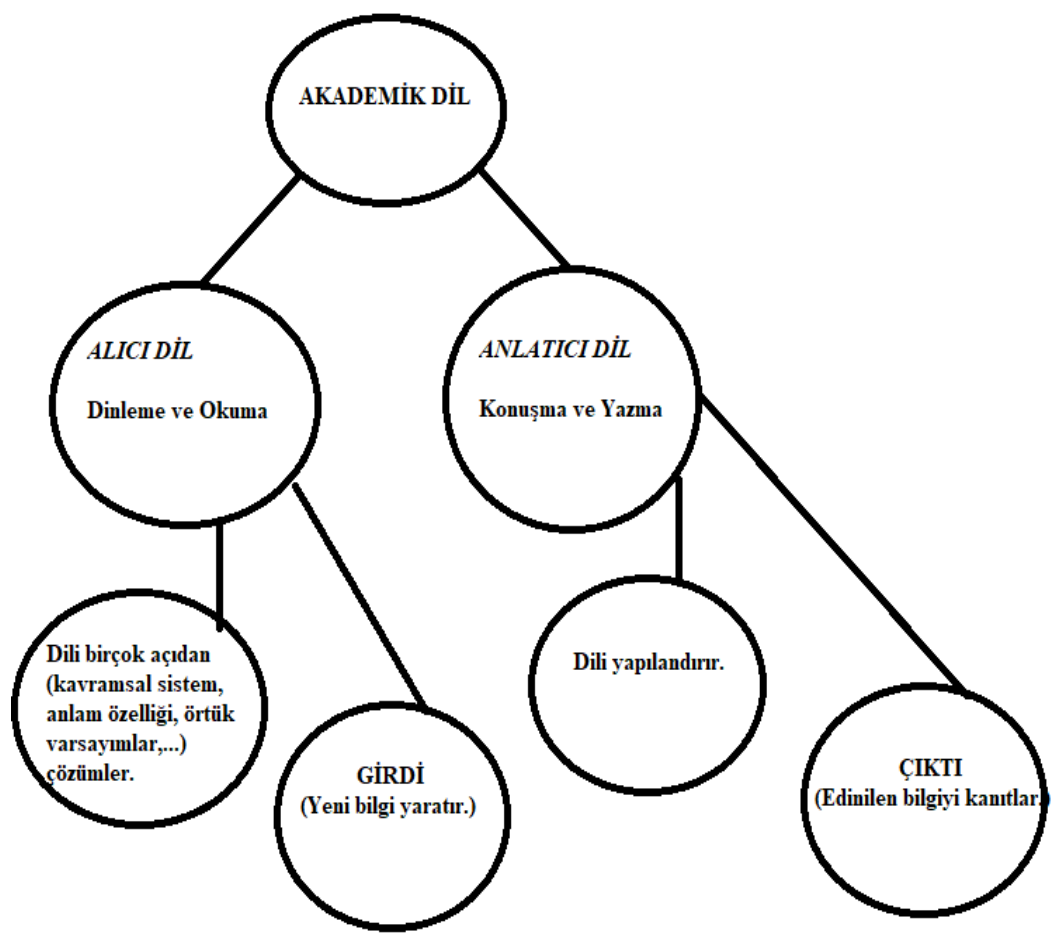

Şekil 1. Akademik Dilin Dört Temel Beceri Ile Bağıntısı (Cook Hirai,vd., 2010, s.32)

Şekil 1'de de görüldüğü üzere akademik dil; girdi ve çıtı döngüsünde dilin alımlayıp yaratımını ve bu yaratımın anlatım becerileri ile aktarımını içerir. Bu süreçte birey, yaratım için alımladığı girdiyi dilin kullanımsal özelliklerine göre yapılandırarak çıtıya dönüştürmektedir. Dilsel girdi üzerine vurgu yapan Krashen (2011), akademik yeterlik için akademik dil yeterliği ve akademik içerik bilgisinin gerektiğini; akademik dil yeterliğinin okuma aracllı̆̆ıyla edinildiğini ve sorun çözme aracllı̆̆ıyla da içerik bilgisinin genişletildiğini dile getirmektedir. Benzer şekilde, içerik odaklı dil öğretiminde dilsel becerilerden çok içeriğe vurgu yapılmakta ve bu öğretim yöntemine göre içerik alanının kullanılması, akademik dilin kullanımını gerektirmektedir ve “öğrencilere dil yeterliliklerini 'genişletme ve derinleştirme' ve 'daha resmî, bağlamsız, bilişsel olarak karmaşık akademik dili’ edinme olanakları sunmaktadır (Crandall ve Tucker, 1990, s. 83). 
Akademik dil öğretimi, dilsel beceri ve içerik alanının yanı sıra kavramsal bağlamda iletişimsel becerilerle de ilişkilendirilmektedir. Hymes (1972), iletişimsel yeti üzerinde dururken bağlamsal dil kullanımında resmî yönü akademik söylemle ilişkilendirmiştir. Halliday (1994), işlevsel dilbilgisine değinmiş ve belirli amaçları başarmak için öğrencinin dilsel kullanımına odaklanarak dilin üç üst-dil işlevini ele almıştır: düşünsel, kişilerarası, metinsel. Cummins (1980), akademik dili iki bağlamda nitelendirmiştir: temel kişilerarası iletişim becerileri (Basic Interpersonal Communication Skills- BICS) ve bilişsel akademik dil yeterliği (Cognitive Academic Language ProficiencyCALP). Bunu da dil yeterliğinin buzdağı görünümü olarak şöyle görselleştirmiştir (Şekil 2):

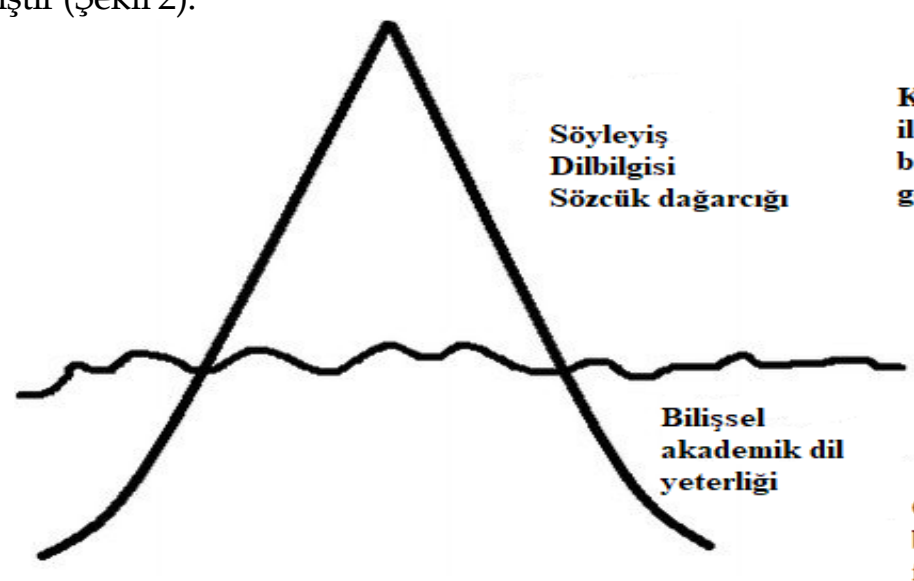

Kişilerarası

iletişimsel

bağlamda dilin

görünümü

Olağan

bağlammdan

farklı akademik

durumlarda dilin

görünümü

Şekil 2. Dil Yeterliğinin Buzdağı Görünümü (Cummins, 1980, s.84)

Temel kişilerarası iletişimsel beceriler, günlük yaşamda; bilişsel akademik dil yeterliği ise sınıftaki akademik konuları anlamak, tartışmak ve ödev ile sinavlarda okuyup yazmak için işe koşulmakta, bu yeterlik için üst dilsel farkındalık öne çıkmaktadır (Cummins, 1980, s.85). Tikunoff (1985, s.26), akademik dil yeterliği kavramını genişleterek üç ayrı kavram eklemiştir: etkileşimli, akademik ve katılımcı yeterlik. Bu üç yeterliği, öğrenci işlevsel yeterliği olarak tanımlayan Tikunoff (1985, s.26), bu yeterliklerden herhangi birinin eksikliğinin bireyin dilsel görevini başarma yeterliğini sınırlandıracağını belirtmektedir. Akademik yeterliliğin kazandırılmasında ise akademik dilin işlev- 
lerinin belirlenmesi öne çıkmaktadır. Akademik dil; çözümleme, sınıflandırma, karşılaştırma, tanımlama, betimleme, sonuç çıarma, değerlendirme, açıklama, varsayımda bulunma, bilgilendirme, anlatma, ikna etme, tahminde bulunma ve bilgi isteme/verme (Dalton-Puffer, 2007, s.129) gibi birçok işlevi içermektedir. Bu işlevlerin işe koşulmasında bireye üstbilişsel beceriyi kazandırma da önem kazanmaktadır (Cook Hirai,vd., 2010; Schleppegrell, 2013).

Üstbilişsel becerinin kazandırılmasında ve bireylerin akademik başarıya ulaşmasında akademik özyeterlik önemli etkenler arasındadır. Akademik özyeterlik, kişilerin belirlemiş oldukları eğitim başarılarına (kazanımlarına) ulaşabilmeleri için gereken eylemleri düzenleyebilme ve yürütme becerilerine ilişkin inançlarıdır (Bandura, 1997) ve öğrencilerin akademik dil öğrenme bağlamında özyeterliklerini geliştirme gereksinimleri, akademik sonuçların iyileştirilmesi için bir temel oluşturmaktadır (Habel, 2009).

Alanyazına bakıldığında, yabancı dil olarak Türkçe öğrenen öğrencilerin akademik dil açısından sorunlar yaşadıkları belirlenmiştir: Akademik dilin öğretilmeyişi ve eğitim ortamında yaşanılan zorluk (Kılıçlar, Sarı ve Seçilmiş, 2012; Biçer, Çoban ve Bakır, 2014; Yahşi Cevher ve Güngör, 2015; Dilek, 2016), akademik Türkçe gereksinimi (Demir, 2017), akademik yazma güçlüğü (Tok, 2013; Demiriz ve Okur, 2019); akademik başarı etkenleri (Yaşar, Özden ve Toprak, 2017) ve akademik başarıda çevre (Paksoy, Paksoy ve Özçalıcı, 2012) ile ilgili sorunlar. Bu sorunların yanı sıra öğrencilerin öğrenim gördükleri lisansüstü alanda akademik özyeterlik algılarının ortaya çıkarılması da bir başka belirleyici etkendir.

Türkiye Yükseköğretim Yeterlilikler Çerçevesi'ne göre yüksek lisans ve doktora öğrencilerinin "alanında edindiği uzmanlık düzeyindeki kuramsal ve uygulamalı bilgileri kullanabilme, edindiği bilgileri farklı disiplin alanlarından gelen bilgilerle bütünleştirerek yorumlayabilme ve yeni bilgiler oluşturabilme, alanı ile ilgili karşılaşılan sorunları araştırma yöntemlerini kullanarak çözümleyebilme, alanı ile ilgili çalışmalarda araştırma yöntemlerini kullanabilmede üst düzey becerileri kazanmış olma,..." gibi becerileri kazanmış olması beklenmektedir (tyyc.yok.gov.tr, 2010). Alanyazına bakıldığında, lisansüstü öğrenim gören öğrencilerin araştırma yöntemleri dersine ilişkin görüşleri (Kurt vd., 2007), araştırma yeterlikleri (Saracaloğlu, 2008; İpek vd.,2010; Çimen, 2011; Akgün ve Güntaş, 2018), öz değerlendirmeleri (Sezgin vd., 2011) ile Türkçe eğitimi programlarındaki öğrencilerin akademik özye- 
terliklerinin (Aslan, 2010) incelendiği görülmektedir. Ancak yabancı öğrencilerin yükseköğretim düzeylerindeki yeterliliklerine ilişkin bir belirleme de ülkemizde eğitim gören bu öğrencilerin sorunlarına çözüm yolları oluşturma açısından önem taşımaktadır. Bu nedenle bu araştırmada lisansüstü öğrenim gören yabancı uyruklu öğrencilerin akademik özyeterliklerine ilişkin görüşlerini belirlemek amaçlanmıştır. Bu amaç doğrultusunda şu sorulara yanıt aranmıştır:

a. Türkçeyi yabancı dil olarak öğrenen bireyler lisansüstü dersleri anlamakta zorluk yaşıyorlar mı? Eğer zorluk yaşıyorlarsa ne gibi zorluklar yaşadıklarına ilişkin görüşleri nelerdir?

b. Derslerle ilgili çalışmalarda Türkçe makale ve tez okuma sıklıkları nedir? Türkçe makale, tez, bildiri okumada zorluk yaşıyorlar mı? Bu zorlukların üstesinden gelmek için neler yaptıklarına ilişkin görüşleri nelerdir?

c. Türkiye'de yapılan kurultay, sempozyum, çalıştay gibi bilimsel etkinliklere katıldılar mı? Eğer katıldılarsa kendileri ile ilgili gözlemleri nelerdir? Katılmadılarsa nedenlerine ilişkin görüşleri nelerdir?

d. Türkçeyi yabancı dil olarak öğrenen bireyler, Türkçe makale yazıyorlar mı? Eğer yazdılarsa herhangi bir sorunla karşılaşıp karşılaşmadıklarına ilişkin görüşleri nelerdir?

e. Türkçeyi yabancı dil olarak öğrenen bireyler, lisansüstü dersler arasında tez yazımı ile ilgili bir ders aldılar mı? Tez yazımını dilsel açıdan kolaylaştırmak adına ne gibi gereksinimleri olduğuna ilişkin görüşleri nelerdir?

\section{Yöntem}

Türkçeyi yabancı dil olarak öğrenen lisansüstü öğrencilerin akademik özyeterlikleri ile ilgili görüşlerini belirlemeyi amaçlayan bu çalışmada odak grup görüşmesi tabanlı nitel yöntem kullanılmıştır.

Nitel araştırmalarda en sık kullanılan yöntemlerden biri olan odak grup görüşmesi, "1lımlı ve tehditkâr olmayan bir ortamda önceden belirlenmiş bir konu hakkında algıları elde etmek amacıyla dikkatle planlanmış bir tartışmalar serisi" olarak tanımlanmaktadır (Yıldırım ve Şimşek, 2008: 152). Odak grup görüşmelerinde, belirlenen bir konu hakkında katılımcıların bakış aç1larına, yaşantılarına, ilgilerine, deneyimlerine, eğilimlerine, düşüncelerine, 
algılarına, duygularına, tutum ve alışkanlıklarına ilişkin derinlemesine, ayrıntılı ve çok boyutlu nitel bilgi edinerek katılımcıların gerçek algı, duygu ve düşüncelerine ulaşılması amaçlanmaktadır (Çokluk, vd. 2011). Bu araştırmada da Türkçeyi yabancı dil olarak öğrenen öğrencilerin lisansüstü eğitim süreçlerine ilişkin duygu, düşünce ve görüşlerini ortaya çıarmak amaçlandığı için bu yöntemden yararlanılmıştır.

\section{Çalışma grubu}

Tablo 1'de katılımcıların demografik bilgilerine yer verilmiştir. Bu bağlamda katılımcıların 5'i (\%42'si) kadın, 7'si (\%58'i) erkektir. Lisansüstü düzey açısından 7'si (\%58'i) yüksek lisans, 5'i (\%42'si) doktora öğrencisidir. Ülke bağlamında bakıldığında, katılımcıların 5'i Suriyeli olmak üzere geriye kalan her bir öğrenci farklı ülkelerdendir.

Tablo 1. Katılımo bilgileri

\begin{tabular}{|c|c|c|c|c|c|}
\hline $\begin{array}{l}\text { Katılımc1 } \\
\text { No } \\
\end{array}$ & Lisansüstü Düzeyi & Yaş & $\begin{array}{l}\text { Cinsi- } \\
\text { yet }\end{array}$ & Anabilim Dalı & Ülkesi \\
\hline 1 & Doktora & 32 & Erkek & Matematik & Nijerya \\
\hline 2 & Doktora & 39 & Kadın & Türk Dili ve Edebiyatı & Suriye \\
\hline 3 & Yüksek lisans & 24 & Erkek & Tarih & Suriye \\
\hline 4 & Yüksek lisans & 29 & Kadın & Temel Eğitim & Suriye \\
\hline 5 & Doktora & 28 & Erkek & Elektrik-Elektronik Mühendisliği & Suriye \\
\hline 6 & Yüksek lisans & 37 & Erkek & Kamu Hukuku & Suriye \\
\hline 7 & Yüksek lisans & 24 & Kadın & İşletme & Senegal \\
\hline 8 & Yüksek lisans & 38 & Erkek & İnşaat Mühendisliği & Kongo \\
\hline 9 & Doktora & 34 & Erkek & Uluslararası Ticaret ve Lojistik & Paraguay \\
\hline 10 & Yüksek lisans & 33 & Kadın & Biyokimya Bilimi ve Teknolojisi & Misir \\
\hline 11 & Yüksek lisans & 27 & Erkek & Kamu Yönetimi ve Siyaset Bilimi & Komor Adaları \\
\hline 12 & Doktora & 29 & Kadın & Biyoloji & Afganistan \\
\hline
\end{tabular}

Tablo 1'de de görüldüğü üzere, katılımcilar, farklı alanlarda lisansüstü eğitim almaktadır. Bu alanların enstitü bağlamında dağılımına bakıldığında, katılımcıların yarısı Sosyal Bilimler Enstitüsüne bağlı anabilim dallarında, \% 42'si Fen Bilimleri Enstitüsü, \% 8'i Eğitim Bilimleri Enstitüsünde lisansüstü öğrenim görmektedir. 


\section{Verilerin Toplanması ve Çözümlenmesi}

Veriler, araştırma amacı doğrultusunda oluşturulan kişisel bilgi formu ve sorular yoluyla toplanmıştır. Odak grup görüşmeleri genel olarak dört aşamada gerçekleştirilmektedir (Çokluk, vd., 2011, 100-101) ve bu dört aşama doğrultusunda verilerin toplanması, işlemlenmesi ve çözümlenmesi yapılmiştır.

Odak grup görüşmesinin aşamaları doğrultusunda araştırmada şöyle bir yol izlenmiştir:

1. Aşama: Bu aşamada, araştırmacı araştıracağı konuyu belirlemekte ve konuyu ayrıntılı bir biçimde inceleyerek sınırlarını çizmektedir. Bu incelemede, konular önem sırasına konulmaktadır. Bu bağlamda, öncelikle lisansüstü öğrenim gören öğrencilerin akademik özyeterlik algıları konu olarak belirlenmiş, ardından öncelikle alanyazın taraması yapılarak konu ile ilgili araştırmalar incelenmiştir. İnceleme sonucunda akademik alanla ilgili alt konu başlıkları belirlenerek konu sınırlandırılmıştır.

2. Aşama: İkinci aşamada, araştırmaya katılacak kişiler, bu kişilerin özellikleri, kişilerin ortak özellikleri, görüşmede kullanılacak ana başlıklar ve sorulacak sorular belirlenmektedir. Bunun için araştırmada katılımcıların ortak yönü olarak lisansüstü öğrenim gören ve ders dönemini tamamlayıp tez aşamasına geçmiş yabancı öğrenciler olması amaçlanmıştır. Bu bağlamda odak grup görüşmesinde öğrencilere sorulacak sorular belirlenmiş ve uzman görüşü alınarak görüşme sorularına son hâli verilmiştir.

3. Aşama: Bu aşamada, odak grup görüşmesinin yeri, zamanı, moderatör, raportör, varsa diğer görevliler belirlenmekte ve görüşme yapılmaktadır. Bunun için lisansüstü yabancı öğrencilere duyuru yapılmış ve öğrencilerle 12.11.2019 tarihinde saat $11^{\prime}$ de toplantı salonunda bir araya gelinmiştir. Öncelikle her bir katılımcıya görüşme öncesinde yapılacak çalışma ile ilgili ön bilgi verilmiştir. Bu konuda gönüllü olup olmadıkları sorulmuş ve onların kişisel bilgilerinin, görüşmede alınacak kayıtların özlük hakları göz önünde tutularak korunacağı bildirilmiştir. Öğrencilerin her birinin gönüllü olup olmadıkları belirlendikten sonra görüşmeye başlanmıştır. Görüşme sırasında kamera ve ses kaydı yapılmış, bunun için araştırmacının yanı sıra 1 kişi raportör ve 1 kişi de kayıt görevlisi olmak üzere 3 kişiyle oturum yürütülmüştür. Oturum bitiminde, kayıtlar bilgisayar ortamına aktarılmıştır. 
Odak grup görüşmesinin dördüncü aşaması, verilerin çözümlenmesi aşamasıdır. Bu aşamada görüşme özetlenmekte, raporlar ve kısa notlar incelenmekte, veriler gözden geçirilmekte, görüşmeler çözümlenmekte ve raporlaştırılmaktadır. Bu nedenle öncelikle kayıt, yazıya dökülmüş; ardından raportörle birlikte kaçırılan bir yer olup olmadığını belirlemek amacıyla metin-kayıt arası yeniden karşılaştırma yapılmıştır. Elde edilen her bir veri, alt problemler bağlamında çözümlenmiştir. Araştırmada toplanan verilerin çözümlenmesinde "betimsel analiz" yapılmıştır. Yıldırım ve Şimşek'in de (2008: 224) belirttiği gibi betimsel analizde "elde edilen veriler, daha önceden belirlenen temalara göre özetlenir ve yorumlanır". Bu bağlamda araştırmacı, görüşme sorularınn her birini bir tema olarak belirleyerek bu temalar altında görüşme sırasında katılımcılar tarafından ifade edilenleri sıralamıştır. Ayrıca görüşmelerde ifade edilen görüşlerden alıntılara da yer verilmiştir.

\section{Bulgular}

Bu bölümde, odak grup görüşmesinde sorulan sorular ve bu sorulara katılımclların verdiği yanıtlara ilişkin bulgu ve yorumlar ele alınmış ve değerlendirilmiştir.

Türkçeyi yabancı dil olarak öğrenen lisansüstü öğrencilerin dersleri anlamada zorluk yaşayıp yaşamadıklarına ilişkin görüşleri

Araştırmaya katılan öğrenciler, lisansüstü dersleri anlamadaki zorluğa ilişkin farklı görüşler dile getirmiştir (Şekil 3):

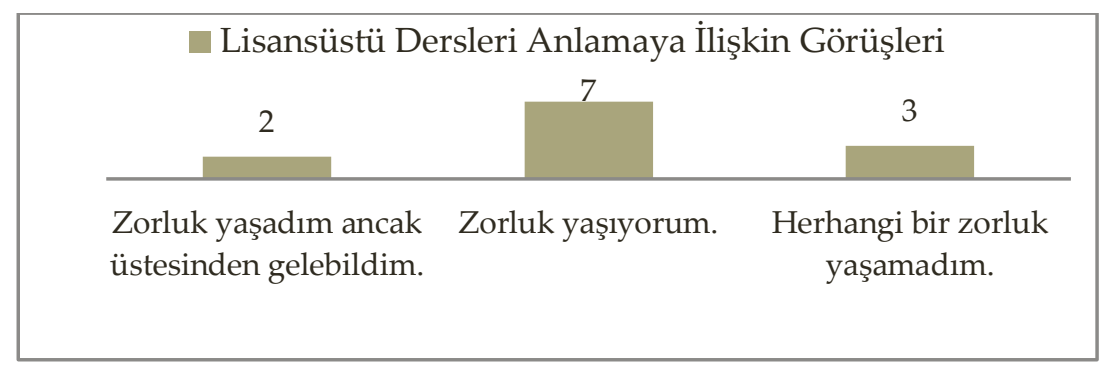

Şekil 3. Katılımcılarn Lisansïstü Dersleri Anlamaya Ilişkin Görüşleri 
Kattlımcıların çoğunluğu (f:7) zorluk yaşadığını belirtirken zorluk yaşamasına karşın üstesinden gelebildiğini belirten yalnızca 2 katılımcı bulunmaktadır. Zorluk yaşamadığını belirten ise 3 katılımcı olmuştur. Katılımcılar, çoğunlukla kaynakları okurken terimlerin bağlamdaki işlevini anlamlandırmakta zorluk yaşadıklarını belirtmişlerdir. Ancak bu zorluk, ders içeriğine göre de değişebilmektedir. Ör; «Bilimsel Etik» dersini yorumlamada güçlük çektiklerini dile getirmişlerdir. Ayrıca dersi dinlerken öğretim üyelerinin ağızsal özellikleri yansıtması ve hızlı konuşması da yaşadıkları zorluklar arasindadır. Bir diğer nokta ise uzun tümceler. Uzun tümcelerin başı ile sonu arasında ilişki kurmakta da yer yer sorun yaşadıklarını; zorlukların üstesinden gelmek için ise dersle ilgili makaleler ya da kaynak kitaplar okumaya çalıştıklarını, internet üzerinden dersler izlediklerini belirtmişlerdir. Zorluk yaşamayanlar ise lisans eğitimlerini Türkiye'de, aynı alanda yapmalarının bir katkısı olduğunu dile getirmişlerdir. Katılımcıların görüşleri şu şekildedir:

- K2: Zorluk yaşıyorum. O da okuma zorluğu. Okumakta fazla hızlı olmadığım için zaman aliyor.

- K3: Evet. Çünkü aldığımız Türkçe TÖMER'de ve derste Türkçede derste farkh bir şey yani. Hem TÖMER'de resmî bir Türkçe ama derste öğretmenler bazıları yani öğretmenler resmî bir şekilde anlatmıyorlar yani, başka bir şekilde yani.

- K5: Bazı derslerde, evet. Çünkü 12 yıl eğitimi farklı bir dilde aldığımdan dolayı bazı bilimsel kelimelerin tam anlamın ve nerde kullamıldı̆̆ı zorluklarım yaşıyorum.

- K6: Hocalar, detaylı açılama yapıyorlar. Anlıyorum.

- K7: Biraz zorluk yaşadım ilk yıllarda. Şimdi çok iyi oldum. Çünkü sürekli kendimi geliştirmeye çalışıyorum.

- K9: Okuma, uzun cümleler. Sunum konuşması çok zor.

- K10: Hoca çok hizh konuşuyor. Şive konuşuyor.

\section{Derslerle ilgili çalışmalarda Türkçe bilimsel çalışmaları (tez, makale, bildiri) okumalarnna ilişkin görüşleri}

Katılımclara Türkçe bilimsel çalışmaları okumalarına ilişkin görüşleri, akademik dergileri takip etme durumları ve YÖK Ulusal Tez Merkezinden yararlanma durumları sorulmuştur. 
Şekil 4'te de görüldügüü üzere, katılımcıların \% 67'si Türkçe akademik dergileri takip etmektedir. Ayrıca katılımcıların \% 42'si YÖK Ulusal Tez Merkezinden yararlanmaktadır. Türkçe yayın okuma durumlarına bakıldığında ise katılımcıların okuma sıklıkları yönünden farklılıklar gösterdiği görülmektedir.
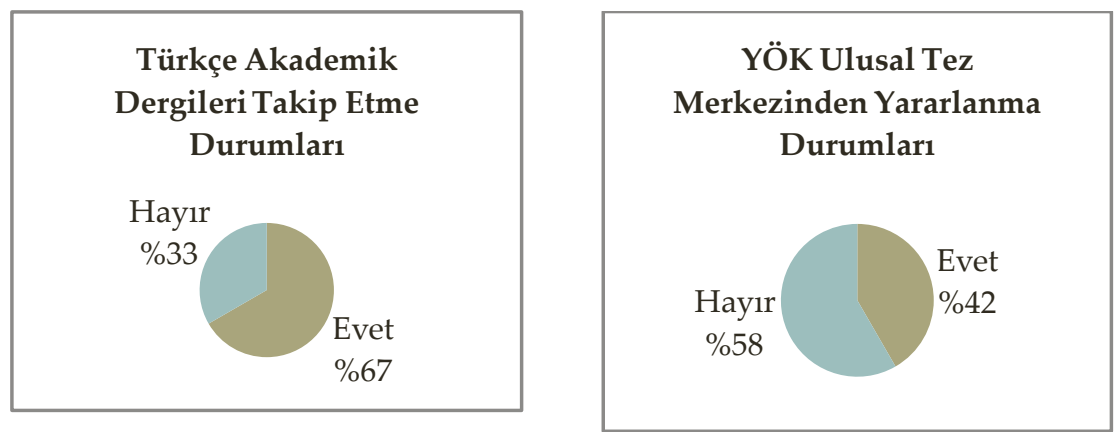

Şekil 4. Katılımcıların Türkçe Yayınlarn Takip Etme Durumları

Katılımcılar, tez dönemine geçince okuma sıklıklarının arttığını, ancak akademik çalışmaları okurken zorluklar yaşadıklarını da belirtmişlerdir (çeviri programlarından yararlanma, makalede anlatılmak istenenlere ilişkin çelişki yaşama gibi). Bu konuya ilişkin şöyle örnek verilebilir:

- K8: Valla, çok okuyoruz bugünlerde. Dönemin sonu olduğu için. Mesela; şimdi bizim dört tane dersimiz var, her dersten yani 3-5 tez okuyoruz.

- K2: Her üç dört günde 1-2 saat ortalama.

- K3: Okuyoruz son senede okuyoruz yani baya okuyoruz. Çünkü teze yaklaşınca baya okuyoruz.

- K9: Haftada bir veya iki makale okuyorum. Makale bilimsel ve dili akademik düzeyde olduğu için ilk önce zorluk yaşadım. Tercüman programları var, onlarn kullandim.

- K4: Günlük en az iki makale ya da bir tez okuyorum. Tez ve makale, bildiri okumada çektiğim zorluklar var. Yani, akademik bilgiler bazen çok farklı. Bazen hangisi doğru hangisi yanlıs̆, anlayamıyorum. 
Türkiye'de yapılan bilimsel toplantılara (sempozyum, kongre, çalıştay) katılma durumlarına ilişkin görüşleri

Katılımcılara Türkiye'de yapılan bilimsel etkinliklere katılma durumu sorulmuş ve yarısından fazlasının katılmadı̆̆ı belirlenmiştir (\% 62).

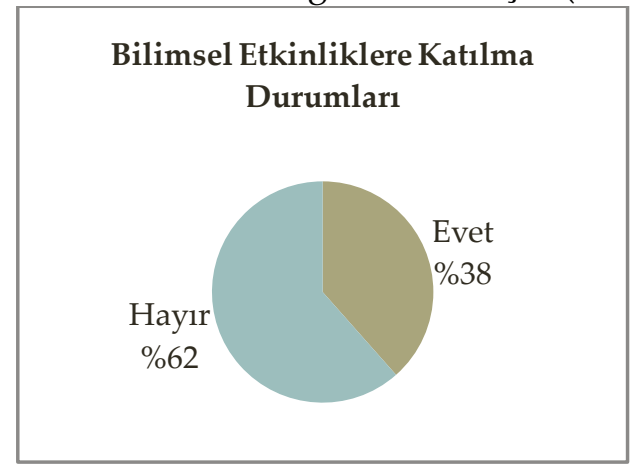

Şekil 5. Katılımcılarn Türkiye'deki Bilimsel Etkinliklere Katılma Durumu

Bilimsel etkinliklere katılanların çoğu, dinleyici olarak katılım göstermiştir. Yalnızca bir katılımcı hocası ile birlikte bildiri sunmak üzere bilimsel toplantıya katıldığını; bir diğer katılımcı da çeviri yapma nedeniyle bir sempozyumda görev aldığını dile getirmiştir. Diğer katılımclar, akademik Türkçe dinleme ve konuşma zorluğu, yeterli bilginin olmaması, kendini hazır hissetmemek gibi nedenlerle konuşmacı olarak katılmadıklarını belirtmişlerdir. Katılımcıların görüşlerine ilişkin şöyle örnek verilebilir:

- K11: Evet, katıldım. Zeugma Kongresi'ne. Dinleyici olarak katıldım. Olumlu bir katılımdi ve çok faydalıydı. Bana daha fazla katılım enerjisi kazandırdı.

- K6: Konuşmacı olarak katılmadım. Çünkü böyle bir firsatım olmadı. Fakat dinleyici olarak katıldim.

- K5: Hayır, katılmadım. Çünkü nasıl katılacağım, bilmiyorum. Bize bilgi verirseniz çok mükemmel olur.

- K7: TICMET 2019'a katıldım. Çok faydalı oldu benim için. Hocamla gittik. Bir bildiri sundum.

- K12: Evet, katıldım ancak tercüman olarak.

- K11: III. Uluslararası Kamu Yönetimi Sempozyumu'na katıldım. Bu bölümde yüksek lisans yapmamda etkili oldu. Ama dinleyiciydim. Hocalarla tanışmak çok güzeldi. 
- K9: Konuşmacı olarak katılmak isterim. Ama Türkçe akademik konuşmak çok zor.

- K1: Şimdi bir sempozyuma bildiri özeti gönderdim. Ancak nasll plan yapacă̆ım, bilmiyorum.

Türkçeyi yabancı dil olarak öğrenen lisansüstü öğrencilerin Türkçe makale yazmalarnna ilişkin görüşleri

Katılımclara Türkçe makale yazıp yazmadıkları sorulmuş, yalnızca \% 33'ü "evet" olarak yanıtlamıştır (Şekil 6). Katılımcıların \% 67'si Türkçe makale yazmadığını belirtirken neden olarak Türkçe yazmanın zor olduğunu, makale yazma aşamalarını öğrenmelerine ve konu alanı ile ilgili araştırma yapmalarına karşın güçlük çektiklerini, ancak yine de bu zorluğun üstesinden gelip makale yazmaya istekli olduklarını belirtmişlerdir. Katılımcıların görüşleri aşağıda belirtilmiştir:

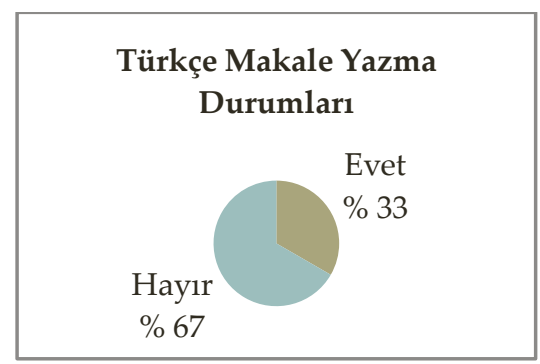

Şekil 6. Katılımcıların Türkçe makale yazma durumlarn

- K1: Yazdım ama İngilizce. Türkçe yazmak çok zor.

- K2: Türkçe makale yazdim ve çok zorluk gördüm. Bunun üstesinden gelmek için çok araştırma yaptım ders konusuyla ilgili ve kaynaklara bakarak, ayrica kitap okumakla bunun üstesinden gelmeye çalışıyorum.

- K3: Evet, yazıyorum. Illk önce bazı bilimsel yazıları ve diğer makaleleri okuyarak yazmaya başladım. Şimdi ise bu sorunlar bazı yönlerden hâlâ devam ediyor.

- K5: Hayır, daha yazmadım. Makale nasıl yazllır, bilmiyordum. Ama şimdi öğrendim ve makale yazmayı çok isterim.

- K6: Yazmadım hâlâ. Bu aşamada kendimi yeterli hissetmiyorum.

- K9: Evet, yazdım. Çok makale okudum ve araştırmalar yaptım makale unsurlarım iyi bilmek için. 
- K10: Hayır, yazmadim. Sadece sunum hazırladım.

- K11: Hayır, sadece ödevlerimi yazdim.

Türkçeyi yabancı dil olarak öğrenen lisansüstü öğrencilerin tez yazımında zorluk yaşayıp yaşamadıklarına ilişkin görüşleri

Araştırmaya katılan her bir öğrenci, araştırma yöntemlerine ilişkin bir ders almıştır. Yalnızca 2 katılımcı (K4 ve K10), tez önerisini vermiş ve tezle ilgili araştırmaya yeni başlamış durumdadır. Diğer öğrenciler, tez dönemindedir. Öğrencilerin tez yazımına ilişkin görüşlerine bakıldığında, tez yazım ilkelerine ilişkin ders almalarına karşın nasıl yazacaklarına ilişkin zorluk yaşadıkları, elde edilen bilgileri birleştirme konusunda güçlük çektikleri ve bu konuda yardıma gereksinim duydukları söylenebilir:

- K1: Bazı dersler aldım. Ama yine de zorluk yaşıyorum. Çünkü biliyorum ama nasıl anlatacă̆ım, bilemiyorum.

- K3: "Sosyal Bilimlerde Araştırma Yöntemleri" diye bir ders aldım. Çok faydalı oldu. Zor ama danışmanım çok yardımcı oluyor.

- K6: Aldım ama yine de biz yabancılar için tez denetimi olması gerektiğini düşünüyorum.

- K5: Ders aldım ama kaynaklarda yardim lazım. Kaynakları okudum ama nasıl birleşecek? Yani, Türkçede nasıl yan yana geliyor?

- K11: Bizim hoca dedi ki "Akış yok. Sen yazarken akış yok. Hep bu konudan atlatıyorsun konuya. Hiçbir akış olmuyor." Çünkü uydurmuyorum. Yani diyorum yani hoca dedi ki "Biraz düzeltmen lazım fikirler girişler, sonra genel bilgiler ama yetersiz olduğu için akış olmuyor."

\section{Tartışma ve Sonuç}

Bu araştırmada lisansüstü öğrenim gören yabancı öğrencilerin akademik özyeterliklerine ilişkin görüşleri belirlenmiştir. Katılımcıların görüşleri doğrultusunda şu sonuçlara ulaşılmıştır:

Katılımcıların çoğunluğu (f:7) anlamada zorluk yaşadığını belirtmiş, bu zorlukların nedeni olarak metin yapısı ve dinleme sırasındaki güçlükleri dile getirmiştir. Ayrıca terimlerin bağlamdaki kullanımı, tümcelerin uzun olması ve konferans konuşmalarının zorluğu da bir diğer yaşanılan sorunlar arasındadır. Bu durum, Dilek'in (2016) çalışmasıyla da örtüşmektedir. Yabancı öğ- 
rencilerin Türkçe algılarını belirlemeyi amaçlayan bu çalışmada, anlama becerilerine yönelik olarak akademik hayatın gerektirdiği dil becerileriyle donatılmamış olmanın onlarda olumsuz etki yarattığı belirtilmiştir. Biçer, Çoban ve Bakır' ın (2014) çalışmasında ise akademik Türkçenin öğretilmeyişinin yanı sıra öğretim görevlilerinin konuşma hızından kaynaklı soruna da vurgu yapılmıştır. Yine Yaşar, Özden ve Toprak'ın (2017) çalışmasında da öğrencilerin akademik dil yetersizliği ve kültürel birikim eksikliği nedeniyle kaynakları okumada sorun yaşadıkları belirlenmiştir. Yahşi Cevher ve Güngör'ün (2015) çalışmasında ise terimleri ve kavramları anlamakta güçlük çektikleri, öğretim görevlilerinin sesletiminin farklı geldiği ve hızlı konuştukları vurgulanmıştır.

Akademik metinlerin bol miktarda terim içermesi, uzun ve karmaşık tümce yapılarına yer vermesi gibi nedenlerle akademik okuma; konuşma hızının konuşana bağlı olması, anlaşılmayan durumlarda geri dönüp tekrar dinleme olanağı vermemesi, standart dışı aksanlara yer verilmesi ise akademik dinlemeyi güçleştirmektedir (Demir, 2017: 56). Ancak uluslararası öğrencilerin akademik gereksinimlerinin başında dilde yeterliliğe ulaşarak ders kitaplarını ve öğretim elemanlarını anlayabilme yetisi gelmektedir (Butcher ve McGrath, 2004: 544). Alanyazında orta ve ileri düzey öğrencilerin okumasına dönük metinlerin yer aldığı birçok kaynak kitap bulunmaktadır. Bu kitaplara bakıldığında, Murphy ve Somay (1988), 1986 yılında gazetelerde yer alan haber metinlerinden yola çıkarak orta düzeydeki öğrencilerin okuduğunu anlama becerisini geliştirmeyi amaçlamıştır. Toplam 36 metinden oluşan kitapta Türkçe metinlerde öne sözcükler ve dilbilgisi yapıları üzerinde durulmuş ve her birinin İngilizce açıklaması yapılmıştır Ayrıca metinlerin İngilizce çevirisi ayrı bir bölümde ele alınmıştır. Yine Symons (2012) tarafından orta düzey öğrencilerine dönük olarak 2004-2010 yılları arasında Türk basınında yayımlanan makalelere yer verilmiştir. Her bir metne ilişkin İngilizce ön bir açıklama yapıldıktan sonra anahtar kavramların Türkçe ve İngilizce karşılıkları, dilbilgisi yapılarının açıklanması ve okuduğunu anlamaya dönük alıştırmalar üzerinde durulmuştur. Örneğin; "Eğitimde Ayrıma Son" başlıklı haber metnini ele alınmadan önce haber metnini anlamlandırmayı kolaylaştırmak için “Türkiye'de Eğitim ve Cinsiyet”" başlıklı makale ile konuya ilişkin İngilizce ön bir bilgi verilmiş, ardından sözcük çalışması, dilbilgisi alıştırması, okuduğunu anlama soruları ve yazma alıştırması ile devam edilmiştir. Yine bir başka kaynak kitap olan "Akademik Türkçe", sosyal bilimler (11 tema) ve 
fen bilimlere ( 5 tema) ait toplam 16 tema altında yabancı öğrencilerin dört temel becerisini geliştirmeye dönük olarak planlanmıştır (Karatay, 2019). Bu bağlamda öğrencilerin akademik metinleri okuyup anlamlandırması ve dinlediğini anlaması yönündeki bu kitaplar, öğrencinin akademik Türkçeye hazırlanması yönünden olumlu bir gelişmedir.

Bir diğer alt problem olan katılımcıların Türkçe yayınları izleme ve okuma durumlarına bakıldığında, \%67'si Türkçe akademik dergileri takip etmekte ve \%42'si YÖK Ulusal Tez Merkezinden yararlanmaktadır. Tez dönemine geçen katılımcılar, akademik yayınları okuma sıklıklarının arttı̆̆ını belirtmesine karşın akademik çalışmaları okurken zorluklar yaşamaktadırlar (çeviri programlarından yararlanma, makalede anlatılmak istenenlere ilişkin çelişki yaşama gibi). Bu çelişki yaşama durumu, Phakiti ve Li'nin (2011) çalışmasıyla örtüşmektedir. Bu çalışmada -anket ve yarı yapılandırılmış görüşme sonucunda- öğrencilerin okudukları metindeki düşünceleri karşılaştırmada zorlandıkları belirlenmiştir. Ayrıca dildeki yeterlik ve akademik özyeterliğin üzerinde akademik güçlüklerin etkili olduğu; genel akademik güçlükler, akademik okuma ve yazma arasında güçlü bir ilişki olduğu ve akademik yazmada bireşim yapmada öğrencilerin güçlük yaşadıkları de belirtilmiştir. Yine Demiriz ve Okur'un (2019) çalışmasında akademik yazmada en çok yanlışlığın anlamsal alanda olduğu belirlenmiştir. Bu da araştırmanın bir diğer problemi olan tez yazım zorluğu ile örtüşmektedir. Çünkü katılımcıların görüşleri doğrultusunda tez yazımına ilişkin ders verilmesine karşın öğrencilerin elde edilen bilgileri birleştirmede güçlük yaşadıkları, bunun için tez denetimi yapacak bir birime gereksinim duydukları belirlenmiştir. Bir diğer bilimsel metin olan makale yazma konusunda ise öğrencilerin \%67'sinin Türkçe makale yazmadığı, makale yazma deneyimi edinmedikleri ve bu konuda kendilerini yetersiz gördükleri sonucuna ulaşılmıştır.

Katılımcıların bilimsel etkinliklere katılma durumlarına bakıldığında, yalnızca \%38'sinin katıldığı belirlenmiştir. Bilimsel etkinliklere katılanlar ise ya dinleyici olarak katılım göstermiş ya da farklı nedenle (çeviri yapma) katılmıştır. Yalnızca 1 katılımcı, hocası ile birlikte bildiri sunmak üzere bilimsel toplantıya katıldığını dile getirmiştir. Katılımcılar, akademik Türkçe dinleme ve konuşma zorluğu, yeterli bilgisinin olmaması, kendisini hazır hissetmemesi gibi nedenlerle konuşmacı olarak katılmadıklarını belirtmişlerdir. Öğrencilerinin konuşma açısından kendilerini yetersiz görmesi, alanyazındaki birçok araştırmada da belirlenmiştir (Kılıçlar, Sarı ve Seçilmiş, 2012; Tunçel, 
2014; Yaşar, Özden ve Toprak, 2017). Cummins ve Man (2007)'e göre akademik konuşma, yüz yüze yapılan günlük konuşmalara oranla geniş bir sözcük dağarcı̆̆ı ve dilbilgisel karmaşıklık bilgisi ile söylem yeterliliğinin olması gerekmektedir.

Sonuç olarak yabancı öğrencilerin akademik Türkçede birçok sorunla karşılaşması, akademik özyeterlik algılarını da olumsuz etkilemektedir. Bu bağlamda dilsel becerilerin akademik alanla ilişkilendirilerek ele alınması, öğrencilerin sorunların üstesinden gelmesinde önemli bir etkendir. Bunun için her bir yabancı öğrencinin lisans ve lisansüstü eğitime başlamadan önce akademik Türkçeye dönük bir eğitim ortamının yapılandırılması önem taşımaktadir. 


\section{EXTENDED ABSTRACT}

\section{The Opinions of Foreign Students Studying for Graduate Studies Related to Their Academic Turkish Language Self-Efficacy \\ Sevil Hasırcı Aksoy \\ Gaziantep University}

Students who learn Turkish as a foreign language have many goals: developing linguistic skills, meeting social-cultural needs, adapting to the academic environment, getting to know the Turkish world closely. In order to adapt academic environment, students need for academic competence. While planning activities for academic language competence, emphasising on the components of academic language will enable these activities to become functional. These components are associated not only with linguistic skills and content, but also with communicative skills in a conceptual context. When the literature was examined, it was determined that students who learn Turkish as a foreign language have problems in terms of academic language. The problems are the difficulties experienced in the educational environment, the need for academic Turkish language, the difficulty of academic writing, the academic failure. In addition, there are also studies on the problems of Turkish graduate students about the research methods course, research competencies, and their self-evaluation. In the literature, besides Turkish students, a determination of the competencies of foreign students at higher education levels is also important in terms of creating solutions to the problems of these students studying in Turkey. Therefore, in this study, it was aimed to determine the views of foreign students studying at the postgraduate level on academic self-efficacy. For this purpose, answers to the following questions were sought:

- Do the postgraduate students who learn Turkish as a foreign language have difficulty in understanding graduate courses? If they have, what are their views on their difficulties?

- What is the frequency of reading Turkish articles and thesis related to their studies? Do they have difficulties in reading articles, theses, and papers 
in Turkish language? What are their views on what they are overcoming these challenges?

- Did they participate in the scientific activities such as workshops, congresses, symposiums in Turkey? If so, what are their observations about themselves? If not, what are their views on the reasons?

- Do the postgraduate students who learn Turkish as a foreign language write articles in Turkish language? If so, what are their opinions on whether they encountered any problems?

- Did the postgraduate students who learn Turkish as a foreign language take a course on thesis writing? What are their views on what kind of requirements they have in order to facilitate thesis writing?

- In this study, a focus group interview-based qualitative method was used in order to find answers to these questions. Of the 12 participants in the study, 7 are master's students and 5 are doctoral students. As a result of the interviews with the participants, the following results were obtained:

- In terms of understanding the graduate courses, while the majority of the participants (f: 7) stated that they had difficulty, there are only 2 participants who stated that they could overcome it despite having difficulty.

- In terms of the frequency of reading articles and thesis in Turkish language, the participants stated that their reading frequency increased when they fell upon the thesis period, but they also stated that they had difficulties while reading academic studies. These difficulties are as follows: benefiting from translation programs, experiencing contradictions regarding what is intended to be explained in the article, etc.

- In terms of scientific activities in Turkey, most of the participants have attended as listeners in symposiums or congress. Most of participants stated that they did not participate as a speaker due to reasons such as difficulty in listening and speaking in academic Turkish, insufficient knowledge, and not feeling ready.

- Participants were asked if they wrote articles in Turkish language, only $33 \%$ of them answered "yes". While $67 \%$ of the participants stated that they did not write articles in Turkish language, they stated that it was difficult to write in Turkish language, that they had difficulties despite learning the stages of article writing and doing research on the subject area. They also declared that they were still willing to overcome this difficulty and write an article. 
- Each student participating in the research has taken a course on research methods. Except for 2 participants, each of them is in the thesis period. Considering the students' views on thesis writing, even if they took courses on the principles of thesis writing, they have difficulties in how to write and combine the obtained information. That's why, they need help in this regard.

In conclusion, in this study, which aims to determine the Turkish perceptions of foreign students, it was found that the students were not equipped with the language skills required by academic life in terms of comprehension skills and this had a negative effect on their academic self-efficacy. In addition, because academic texts include abundant terms and long and complex sentence structures, and the inability to return and listen again with the reason of the speaker's speed and accent, the postgraduate foreign students encounter in so many difficulties in the academic life. Inadequate knowledge of academic discourse and complex grammatical structures also enhance the difficulties experienced. This situation negatively affects students' academic self-efficacy and decreases their frequency of reading academic articles, thesis and their willingness to participate in academic activities.

\section{Kaynakça / References}

Akgün, Ö.E. ve Güntaş, S. (2018). Lisansüstü öğrencilerinin bilimsel araştırma yeterliliklerinin danışman görüşlerine dayalı olarak incelenmesi: Kuzey Kıbrıs Türkiye Cumhuriyeti örneği. Sakarya University Journal of Education, 8(2), 131-144.

Aslan, C. (2010). Türkçe eğitimi programlarında lisansüstü öğrenim gören öğrencilerin akademik özyeterliklerine ilişkin görüşleri. Mehmet Akif Ersoy Üniversitesi Eğitim Fakültesi Dergisi, 19, 87-115.

Bandura, A. (1997). Self-efficacy: The exercise of control. United States of America: W. H. Freedmanand Company.

Barın, E. (2010). Yabancılara Türkçe öğretiminde metodoloji. III. Uluslararası Dünya Dili Türkçe Sempozyumu, 12-16 Arallk 2010 İzmir'de sunulan bildiri.

Biçer, N., Çoban, İ. ve Bakır, S. (2014). Türkçe öğrenen yabanc öğrencilerin karşılaştğı sorunlar: Atatürk Üniversitesi örneği. Uluslararası Sosyal Araştırmalar Dergisi, 7(29), 125-135.

Butcher, A. ve McGrath, T. (2004). International students in New Zealand: needs and responses. International Education Journal, 5(4), 540-551. 
Cook Hirai,D.L., Borrego, I., Garza, E. ve Kloock, C.T. (2010). Academic language/literacy strategies for adolescents a "how to" manual for educators. New York: Routledge Press.

Crandall, J. ve Tucker, G.R. (1990). Content-based language instruction is second and foreign languages. S. Anivan (Ed.). Language teaching methodology for the nineties içinde (s. 83-96). Singapore: SEAMEO Regional Language Centre.

Cummins, J. (1980). The construct of language proficiency in bilingual education. J. E. Alatis (Ed.). Georgetown University Roundtable on Languages and Linguistics içinde (s. 76-93). Washington, DC: Georgetown University Press.

Cummins, J., ve Man, E. Y.-F. (2007). Academic language: What is it and how do we acquire it? J. Cummins ve C. Davison (Eds.). International handbook of English language teaching, içinde (s.797-810). New York: Springer.

Çimen, O., Yılmaz, M. ve Çimen, G. (2011). Biyoloji eğitimi yüksek lisans öğrencilerinin lisansüstü yeterliklerine ilişkin görüşleri. 2nd International Conference on New Trends in Education and Their Implications- 27-29 Nisan, Antalya. http://www.iconte.org/FileUpload/ks59689/File/2011.international conference.pdf adresinden 1 Ocak 2020 tarihinde erişilmiştir.

Çokluk, Ö., Yılmaz, K. ve Oğuz, E. (2011). Nitel bir görüşme yöntemi: odak grup görüşmesi. Kuramsal Ĕ̈itimbilim, 4 (1), 95-107.

Dalton-Puffer, C. (2007). Discourse in content and language integrated learning (CLIL) classrooms. Amsterdam: John Benjamins.

Demir, D. (2017). Uluslararası öğrencilerin akademik Türkçe ihtiyaçları. Yayımlanmamış doktora tezi. Ankara: Hacettepe Üniversitesi Türkiyat Araştırmaları Enstitüsü.

Demiriz, H. N. ve Okur, A. (2019). Türkçe öğretiminde yazma öğretimine akademik Türkçe aşamasında yabancı öğrenciler üzerinden bir bakış. Ana Dili Eğitimi Dergisi, 7(2), 436-449.

Dilek, İ. (2016). Türkçeyi yabanc dil olarak öğrenen uluslararası öğrencilerde ve eğitim dili Türkçe olan üniversitelere gidenlerde Türkçe algısı. Aydın TÖMER Dil Dergisi, 1(2), 17-32.

Goldenberg, C., ve Coleman, R. (2010). Promoting academic achievement among English learners: A guide to the research. Thousand Oaks, CA: Corwin Press.

Habel, C. (2009). Academic self-efficacy in ALL: Capacity-building through self-belief. Journal of Academic Language \& Learning, 3 (2), A-94-104.

Halliday, M.A.K. (1994). An introduction to functional grammar. London: Edward Arnold. Hymes, D. (1972). Introduction. C. B. Cazden, V. P. John, ve D. Hymes (Eds.), Functions of language in the classroom içinde (s. i-vii). New York: Teachers College Press. 
İpek, A. C., Tekbıyık, A. veUrsavaş, Ö.F. (2010). Lisansüstü öğrencilerinin araştırma özyeterlik inançları ve bilgisayar tutumları. Gaziantep Üniversitesi Sosyal Bilimler Dergisi, 9(1), 127-145.

Kılıçlar,A., Sarı,Y. ve Seçilmiş, C. (2012). Türk dünyasından gelen öğrencilerin yaşadıkları sorunların akademik başarılarına etkisi: turizm öğrencileri örneği. Bilig, 61, $157-172$.

Krashen, S. (2011). Academic proficiency (language and content) and the role of strategies. TESOL Journal, 2(4), 381-393.

Kurt, A. A., Yıldırm, Y., Becit, G., Uysal, Ö., Bağcı, H. ve Özdamar, N. (2007). Sosyal bilimlerde araştırma yöntemleri dersine ilişkin öğrenci görüşleri. III. Lisansüstü Ĕ̆itim Sempozyumu Bildiri Kitabl-2007 içinde(s. 371-379), Eskişehir: Anadolu Üniversitesi.

Murphy, J.D. ve Somay, M. (1988). Turkish newspaper reader. Wheaton, Maryland: Dunwoody Press.

Newton, J. M., Ferris, D. R,, Goh, C. M., Grabe, W., Stoller, F. S., ve Vandergrift, L. (2018). Teaching English to second language learners in academic contexts: Reading, writing, listening, and speaking. New York: Routledge.

Paksoy, H.M., Paksoy, S. ve Özçalıcı, M. (2012). Türkiye'de yüksek öğrenim gören yabancı uyruklu öğrencilerin sosyal sorunları: GAP bölgesi üniversiteleri örneği. Kahramanmaraş Sütçü Imam Üniversitesi İktisadi ve İdari Bilimler Fakültesi Dergisi, 2(2), 85-94.

Phakiti, A., ve Li, L. (2011). General academic difficulties and reading and writing difficulties among Asian ESL postgraduate students in TESOL at an Australian university. RELC Journal, 42(3), 227-264.

Saracaloğlu, A. S. (2008). Lisansüstü öğrencilerin akademik güdülenme düzeyleri, araştırma kayglanı ve tutumları ile araştırma yeterlikleri arasındaki ilişki. Yüzüncü Yıl Üniversitesi Ĕ̆itim Fakültesi Dergisi, 5(2), 179-208.

Scarcella, R. (2003). Accelerating academic English: A focus on the English learner. Oakland, CA: Regents of the University of California.

Schleppegrell, M. J. (2013). The role of metalanguage in supporting academic language development. Language Learning, 63(1), 153-170.

Sezgin, F., Kavgacı H. ve Kılınç, A. Ç. (2011). Türkiye'de eğitim yönetimi ve denetimi lisansüstü öğrencilerinin öz değerlendirmeleri. Yükseköğretim ve Bilim Dergisi, 1(3), 161-169. 
Suna, Ç., Karadağ, R. ve Ay, T. S. (2007). Yüksek lisans programı öğrencilerinin bilimsel araştırma sürecinde karşılaş̧lan sorunlara ilişkin görüşleri. III. Lisansüstü Ĕ̆itim Sempozyumu Bildiri Kitabı- 2007 içinde (s. 448-456), Eskişehir: Anadolu Üniversitesi.

Tikunoff, W.J. (1985). Applying significant bilingual instructional features in the classroompart c bilingual education research series. Wheaton, Maryland: National Clearinghouse for Bilingual Education.

Tok, M. (2013). Türkçenin yabancı dil olarak öğretiminde akademik yazma ihtiyacı. Mustafa Kemal Üniversitesi Sosyal Bilimler Enstitüsü Dergisi, 10 (23), 1-25.

Tunçel, H. (2014) Yabancı dil öğretimine yönelik kaygı çalışmalarına genel bir bakış. Route Educational and Social Science Journal, 1(2), 126-151.

Yahşi Cevher, Ö. ve Güngör, C. (2015). Yabancı dil olarak Türkçe öğretiminde akademik Türkçenin önemine ilişkin uygulamalı bir araştırma: Türk dili öğretimi uygulama ve araştırma merkezi örneği. IJLET, UDES 2015 Özel Sayısı, 22672274.

Yaşar, E., Özden, M. ve Toprak, S. (2017). Türkçenin yabancı dil olarak öğretiminde TÖMERler ve akademik başarı. International Journal of Languages' Education and Teaching, 5(3), 213-224.

Yıldırım, A. ve Şimşek, H. (2008). Sosyal bilimlerde nitel araştırma yöntemleri (6. Baskı). Ankara: Seçkin Yayıncılık.

YÖK (2010). Türkiye yükseköğretim yeterlilikler çerçevesi. http://tyyc.yok.gov.tr/?pid=35 adresinden 30.01.2020 tarihinde erişilmiştir.

\section{Kaynakça Bilgisi / Citation Information}

Hasırcı Aksoy, S. (2021). Lisansüstü öğrenim gören yabancı öğrencilerin akademik Türkçe özyeterliklerine ilişkin görüşleri. OPUS-Uluslararası Toplum Araştırmaları Dergisi, 17(35), 1705-1728. DOI: 10.26466/opus.771216 